\title{
Family Expressed Emotion In Relapse of Alcoholism
}

\author{
Githae, Eunice Njango \\ Psychology Department: Kenyatta University, Kenya
}

\begin{abstract}
Alcoholism is a family illness that requires treatment of the whole family, because recovery after rehabilitation seems mostly achievable when both the individual and their family are involved in relapse prevention. While studies have demonstrated that the family plays an important role from the diagnosis to treatment of alcoholism, few studies have focused on the interpersonal dynamics of family members which would maintain alcoholism relatedbehaviors and lead to relapse. Such interpersonal dynamics include the family emotional expression (EE) and how it may relate to relapse of an individual dependent on alcohol. The relationship between family $\mathrm{EE}$ and the occurrence of relapse in alcoholism was examined. The study was underpinned by the Family Systems Theory to help understand how complex interactional patterns among family members were likely to maintainmaladaptive behaviors such as alcoholism. Samples were derived from populations of inpatient individuals that were addicted to alcohol $(\mathrm{N}=186)$ and their family members in Nairobi, Kenya. The study found out that $E E$ had a predictive value $\mathrm{R}^{2}=.348$ and was statistically significant at $\mathrm{p}=0.000<0.05$. While hostility was found to have an inverse relationship with relapse $(\beta=-.133)$, criticism was found to predict relapse at $\mathrm{R}^{2}=.282$ and over-involvement at $\mathrm{R}^{2}=.471 \%$. The study concluded that high levels of family EE were a significant in predicting relapse of an individual dependent on alcohol during the recovery process.
\end{abstract}

Keywords: Expressed emotion, alcoholism, patient, abstinence, emotional over-involvement.

\section{INTRODUCTION}

Treatment of addictive disorders in the recent years has focused on relapse prevention as an important component during recovery (Marlatt, Parks \& Witkiewitz, 2002). Robust studies in this area have supported the view that individual factors are responsible for causing relapse (e.g. Witkiewitz \& Marlatt, 2004) while many other studies have recognized that the social context particularly the family has a significant role to play in maintaining abstinence after treatment of alcoholism (e.g. Copello, Velleman \& Templeton, 2005; Saatcioglu, Erim \& Cakmak, 2006). A supportive family is considered the strongest source of identity and social support among all contextual relationships (Beattie, 2001) and hence is associated with better prognosis during alcoholism treatment. The family Systems Theory (Minuchin, 1974) has perhaps put forward the strongest support for the role of patterns and processes of communication in psychopathology (L'Abate, 1998; West, 2006). The family is conceptualized as a dynamic system that changes over time whereby individual members have a considerable degree of "circularity of influence" on each other (Nichols \& Schwartz, 2006) and that the individual suffering from a maladaptive behavior is an 'identified patient' representing the level of disturbance or dysfunctionality in the family (Goldenberg \& Goldenberg, 2000). Following this argument, family interactions are likely to affect the course of alcoholism within a family that has a member who is dependent on alcohol.

Arguments for the role of family in the course of alcoholism have contributed to a high impetus in the expansion of scope of effectiveness in alcohol treatment to include the family members (Copello et al., 2005). Family is considered part of the solution to the relapse problem without which the individual would likely give up on his abstinence goal (Pierce, Frone, Russell, Cooper, \& Mudar, 2000). Family treatment for alcoholism aims at improving communication among its members and motivatingthe individual dependent on alcohol to remain abstinentafter treatment,hence therapy given to the whole family enhances positive family functioning, which in turn is likely to improve prognosis (Antoine, Christophe, \& Nandrino, 2009).

Although robust studies indicate that family members are a rich source of support during treatment, there is evidence that some family interactions, which appear to be supportive, may in fact promote relapse (Orford, Velleman, Copello, Templeton, \& Ibanga, 2010). Some interactional patterns such as high expressed emotion (EE) among family membersare counterproductive in anyattempts to offer treatment for alcoholism (Raitasalo \& Holmila, 2005). Family members sometimes use coping strategies such as pouring out alcoholic drinks, pleading for change, ignoring the addicted individual when drunk, nagging about previous or current drinking, threats to abandon them if they don't stop, joining them for a drink, and many other forms of manipulative tactics (Chan, 2003; Fals-Stewart, O’Farrell, Birchler, Cordova,\& Kelley, 2005; Hunter-Reel, McCrady, \& Hildebrandt, 2009). Such strategies have been found to reinforce dependency on alcohol because 
they protect the dependent individual from facing the negative consequences of theirmaladjusted actions (Chan 2003; Collins, 1990).This study focused on the role of the family interactional pattern referred to as emotional expression (EE) in the course of alcoholism. EE is a pattern characterized by hostility, criticism, and emotional over-involvement towards a patient with a psychological problem such as alcoholism(Rotunda and O'Farrell 1998; Hooley, 2007). Hostilityis evidenced by an expression of anger, resentment, irritability, assault, and antagonism by relatives of a patient with a psychiatric problem because they viewthe individual asresponsible for their difficulties. Criticism on the other hand involves expressing disapproval and dislike to something that the patient does (Simmons, Chambless, \& Gordon, 2008). In sharp contrast, emotional over-involvement (EOI) is a tendency to be overly protective of the patient and being over-concerned, devoted, and self-sacrificing to the patient (Hooley \& Gotlib, 2000; Rotunda and O'Farrell 1998). EE is a characteristic of family members and not necessarily of the patients themselves (Hooley, 2007).

EE has been associated with poor outcome and relapse in a variety of psychopathologies and began with studies on schizophrenic patients (Brewin, MacCarthy, Duda, \& Vaughn, 1991; Hooley, 2007). A series of studies have demonstrated a clear association between high levels of family EE and relapse among psychiatric patients in various illnesses such as schizophrenia (e.g. Carlson, 2011; Ikram, Suhail, Jafery, \& Singh, 2011; Ng, Mui, Cheung \& Leung, 2001), depression and other mood disorders (Simmons, et al., 2008; Klaus \& Fristad, 2005; Kwon, Lee, Lee, \& Bifulco, 2006), agoraphobia (Chambless \& Steketee, 1999), and suicidal behavior and self-concept (Santos, Saraiva \& De Sousa, 2009).

While majority of studies done have provided support for the association between family expressed emotion (EE) and relapse, such information is however equivocal. Some findings have offered evidence of EErelapse association while other studies are at odds with proponents of EE-relapse association. For instance among studies with schizophrenic patients, Azhar and Varma (1996) and Lopez, Ramirez, Ullman, Kopelowicz, Jenkins, Breitborde, \& Placenia (2009) found no association between EE and relapse. Few studies have attempted to replicate EE-relapse association with patients with alcoholism (e.g. O'Farrell, Hooley, Fals-Stewart and Cutter 1998; Fichter, Glynn, Weyerer, Lieberman, \& Frick, 1997; Hooley, 2007: Pugovkina, \& Popinako, 2014). Such studies argue that there is greater expression of hostility, negative judgment, and lack of socially positive attitudes among family membershaving a patient with alcohol dependence (Pourmand, Kavanagh, \& Vaughan, 2005; Pugovkina, \& Popinako, 2014). Though many of these replicated studies allude to the consistency of the EE-relapse association (e.g. Renshaw, Blais, \& Caska, 2010; Simmons, et al., 2008; Pourmand, Kavanagh, \& Vaughan, 2005; Hooley, 2007), some other studies found such a relationship weak. For instance Fichter et al (1997) demonstrated that though EE was significant in alcoholism relapse, one of the constructsthat is emotional over-involvement (EOI) did not support relapse of a recovering individuals with alcohol dependence. It is also noteworthy that majority of suchstudies on EE-relapse association were done with Western populations and it would be necessary to establish the relationship between the variables among otherdiverse cultures.

\section{METHODOLOGY}

The population of this study was made up of 10 rehabilitation centers in Nairobi Kenya, whereby a census sampling was done for all inpatient individuals with alcoholism in these centers and their family members. A battery of questionnaires was used to examine the relationship between family expressed emotion (EE) and relapse from 186 inpatient individuals with alcohol dependency in rehabilitation centers in Nairobi and their family members. The inpatients in treatment centers responded to the Alcohol Use Disorders Identification Test (AUDIT) to assess for alcoholism, and an Individual Attitude Scale (IAPS) to assess for perception of EE. EE of the family member was assessed using the Family Member Attitude Scale (FMAS), which was a mirror to the IAPS but with a change in the pronoun. Both the IAPS and FMAS were a combination of questions adopted from Family attitude Scale (FAS), Perceived Criticism measure (PCM) and Family Emotional Involvement and Criticism Scale (FEICS II). The statements were measured on a 5-point Likert scale, where the respondents were asked to indicate on a scale of 1 'strongly disagree' to 5 'strongly agree' whether the statements reflected their perception or expression of EE. The individual with alcoholism had to have lived with a family member or a family equivalent prior to admission. This was a relative or family equivalent who was concerned about the drinking problem and who had more than 35 hours of face-face contact with the respondent per week. The IAPS demonstrated a reliability of 0.789 , while the FMAS indicated a reliability of 0.790 respectively. Structured interviews were also conducted with 20 of the inpatients and their family members and the interview data corroborated with data derived from the questionnaires. Data corrected was subjected to two types of analysis: in order to gain a clear perspective into the socio demographic characteristics of the respondents, frequency distributions were employed, while correlation analysis and regressions were used to test the hypotheses.

The main objective of the study was to find out if there existed a relationship between family EE (hostility, criticism and emotional over-involvement) and relapse in alcoholism. The relationship of the components of EE and relapse are depicted in the schematic diagram below. 


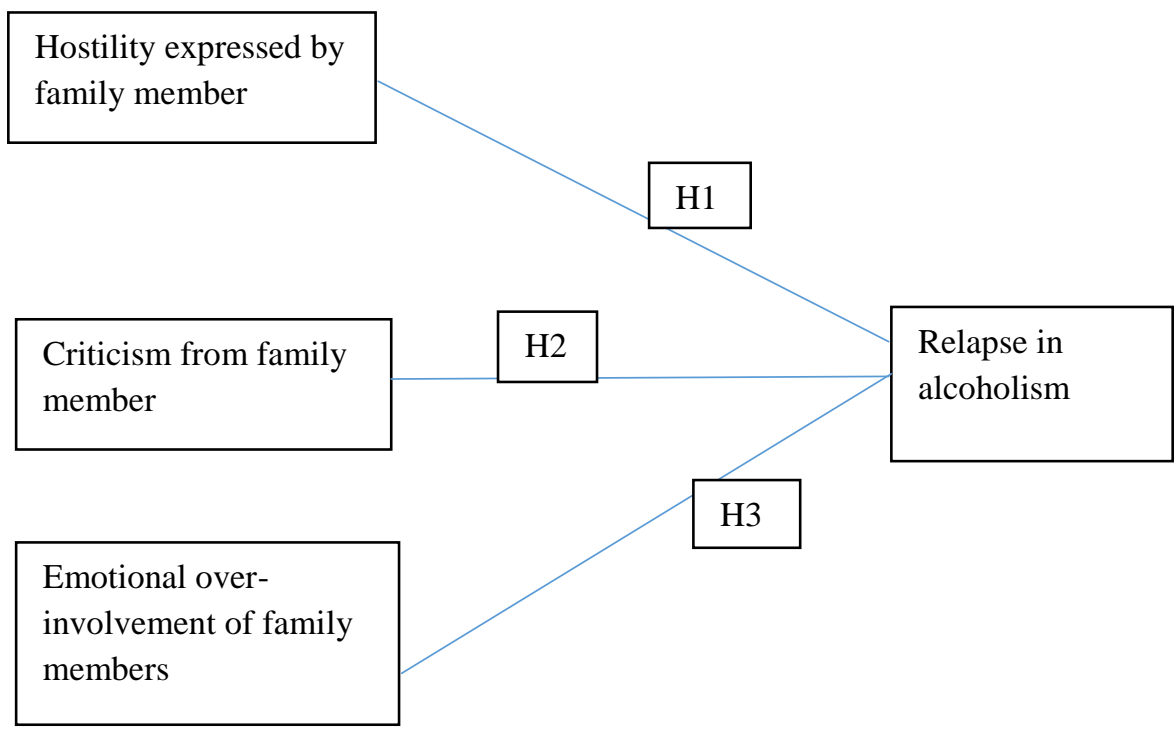

Figure 1: Conceptual Framework

Research Hypotheses:

In order to achieve the objectives designed for this study, the following research hypotheses were formulated:

$\mathrm{H}_{0}$ : There is no significant relationship between family EE (characterized by hostility, criticism, and emotional involvement) and relapse in alcoholism.

$\mathrm{H}_{\mathrm{a}}$ : There exists a significant relationship between family EE (characterized byhostility, criticism, and emotional involvement) and relapse in alcoholism.

\section{FINDINGS}

The mean age of the inpatients with alcohol dependency was $27 y e a r s$ while that of family members was 43 years. Most of the dependent individuals were male $95 \%$ and single $55.3 \%$. The family members were mainly female $81 \%$ and with mothers to the inpatients as the main respondents at $55 \%$. According to the findings, $39.2 \%$ of the inpatients had relapsed over the past three year period. The operational definition for relapse was readmission to a treatment center for alcoholism after earlier treatment within the course of three years. Out of the readmitted respondents, $34.2 \%$ had been readmitted once, $45.2 \%$ twice, $12.2 \%$ three times, and $8.2 \%$ had been readmitted more than three times within a three year period.

On average both populations demonstratedhigh levelsof EE, an indication that the family members expressed hostility, criticism and emotional over-involvement (EOI), while on the other hand the individuals dependent on alcohol perceived the EE expressed by family members. As shown on Fig. 2 below, the means of both populations of the study (inpatient dependent individuals and family members) showed that majority of the respondents mainly 'agreed'or 'strongly agreed' to statements indicating high hostility, criticism and emotional over-involvement (EOI). Fewer numbers 'disagreed' or 'strongly disagreed' to the statements and the findings hence indicated that high EE existed in their families.EOI had the highest positive votes from both groups of respondents, which meant that majority of the study respondents agreed that EOI was a major characteristic of their families. According to Hooley (2007) a family is characterized as having high EE when there is presence of expression of hostility, criticism and EOI. However, the expressed emotion has no implication if it is not perceived by the recipient (Rotunda \& O'Farrell, 1998). The study findings demonstrated that the expressed emotion by a family member was also perceived by the recipient who was the family member that was suffering alcoholism. It is notable that the total responses for 'agree' and 'strongly agree' for both populations were higher for all the components of EE, which was a likely indication that high EE was a characteristic feature of interaction patterns among families with an individual addicted to alcohol.This is summarized in Figure 2. 


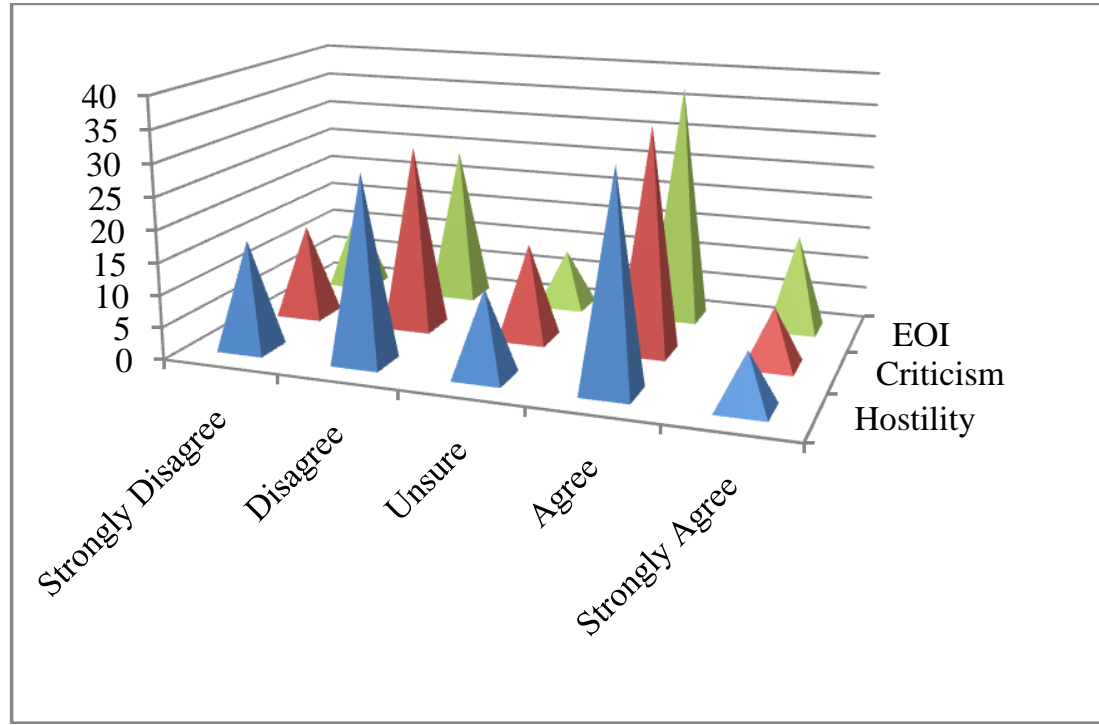

Figure 2. Expressed Emotion by Recovering Inpatients and Family Members.

\subsection{Correlation between EE and relapse}

In order to establish the exact nature of relationship between relapse and the components of EE (hostility, criticism and EOI) the Pearson Correlation Coefficient (r) was applied. All the variables had a positive correlation with relapse. The $r$ value of hostility was $.367(\mathrm{p}=0.000<0.01) ; r$ value for criticism was .367 $(\mathrm{p}=0.000<0.01)$; and the $\mathrm{r}$ value for EOI was $.520(\mathrm{p}=0.000<0.01)$. All EE variables of hostility, criticism, and EOI had a significantly positive impact on relapse of the individuals recovering from alcohol dependency. Criticism and hostility had an equal association with relapse and that all the EE variables (hostility, criticism, and EOI) had a positive and strong relationship with each other. Hostility and criticism correlates showed $\mathrm{r}=0.498,(\mathrm{p}=0.000<0.01)$, hostility and EOI correlated at $\mathrm{r}=0.674(\mathrm{p}=0.000<0.01)$, criticism and EOI at $\mathrm{r}=.278$ $(\mathrm{p}=0.000<0.01)$, while criticism and hostility had a value of $\mathrm{r}=.498(\mathrm{p}=0.000<0.01)$. These findings indicate that all three variables had a positive correlation with each other and were statistically significant with each other, that is, where an increase in one meant there would be an increase in the other.

Based on the findings of the correlation analysis of $\mathrm{EE}$ and relapse in alcoholism, $\mathrm{H}_{0}$ (there is no relationship between family EE and relapse in alcoholism) was rejected in the study and therefore the alternate hypothesis $\mathrm{H}_{1}$ was accepted. That is, there was a positive relationship between EE and relapse in alcoholism. Table 1 summarizes the correlational analysis of relapse in alcoholism and the components of EE (hostility, criticism, and EOI).

Table 1: Correlation matrix for Relapse and EE Variables

\begin{tabular}{|c|c|c|c|c|c|}
\hline & & Relapse & Hostility & Criticism & EOI \\
\hline \multirow[t]{3}{*}{ Relapse } & Pearson Correlation & 1 & $.367^{* *}$ & $.367^{* *}$ & $.520^{* *}$ \\
\hline & Sig. (2-tailed) & & .000 & .000 & .000 \\
\hline & $\mathrm{N}$ & 179 & 177 & 174 & 177 \\
\hline \multirow[t]{3}{*}{ Hostility } & Pearson Correlation & $.367^{* *}$ & 1 & $.498^{* *}$ & $.674^{* *}$ \\
\hline & Sig. (2-tailed) & .000 & & .000 & .000 \\
\hline & $\mathrm{N}$ & 177 & 182 & 179 & 182 \\
\hline \multirow[t]{3}{*}{ Criticism } & Pearson Correlation & $.367^{* *}$ & $.498^{* *}$ & 1 & $.278^{* *}$ \\
\hline & Sig. (2-tailed) & .000 & .000 & & .000 \\
\hline & $\mathrm{N}$ & 174 & 179 & 179 & 179 \\
\hline \multirow[t]{3}{*}{ EOI } & Pearson Correlation & $.520^{* *}$ & $.674^{* *}$ & $.278^{* *}$ & 1 \\
\hline & Sig. (2-tailed) & .000 & .000 & .000 & \\
\hline & $\mathrm{N}$ & 177 & 182 & 179 & 182 \\
\hline
\end{tabular}


A test for multicollinearity was done to measure whether there was any association among the variables in the regression model. This test was particularly done to show the association between hostility and criticism which had indicated a similar correlation coefficient $(\mathrm{r}=.367, \mathrm{p}=0.000<0.01)$. This is summarized on Table 2.

Table 2: Test for Multicollinearity

\begin{tabular}{|c|c|c|}
\hline \multirow[t]{2}{*}{ Model } & \multicolumn{2}{|c|}{ Collinearity Statistics } \\
\hline & Tolerance & VIF \\
\hline (Constant) & & \\
\hline Hostility & .449 & 2.228 \\
\hline Criticism & .749 & 1.335 \\
\hline EOI & .550 & 1.820 \\
\hline
\end{tabular}

The findings confirmed that the VIFs were down to an acceptable range below 5, hence there was nofear of multicollineality among the predictor variables with hostility at $2.228<5$, criticism had $1.335<5$, while EOI was at $1.820<5$. Hence the relationship among the predictor variables did not influence each other to a level of interfering with their different association with the dependent variable (relapse).

To further clarify the nature of the relationship and determine the predictive power of the explanatory variables (criticism, hostility, and EOI) on relapse in alcoholism, regression analysiswas applied and the findings areas displayed on Table 3.

Table 3: Model Summary

\begin{tabular}{|l|l|l|l|l|}
\hline Model & R & R Square & Adjusted R Square & Std. Error of the Estimate \\
\hline Dimension & $.590^{\mathrm{a}}$ & .348 & .337 & 12.41170 \\
\hline
\end{tabular}

a. Predictors: (Constant), EOI, Criticism, Hostility

Table 3 shows that the value of $\mathrm{R}$ Square was .348 which is the explained variance in the dependent variable. According to the findings, the $\mathrm{R}^{2=} 0.348$, which implied that $34.8 \%$ of the variations in relapse were adequately explained by family criticism, hostility and family over-involvement scores in this study. The beta coefficients of the predictor variables from the model gave a clearer view of the level of significance for each predictor variable as shown on Table 4 below.

Table 4: Coefficients for Study Variables

\begin{tabular}{|c|l|l|l|l|l|}
\hline \multirow{2}{*}{ Model } & \multicolumn{2}{|l|}{$\begin{array}{l}\text { Unstandardized } \\
\text { Coefficients }\end{array}$} & \multicolumn{2}{l|}{$\begin{array}{l}\text { Standardized } \\
\text { Coefficients }\end{array}$} & \multirow{2}{*}{} \\
\cline { 2 - 4 } & B & Std. Error & Beta & T & Sig. \\
\hline (Constant) & 44.086 & 5.139 & & 8.578 & .000 \\
Hostility & -.451 & .314 & -.133 & -1.437 & .152 \\
Criticism & .944 & .239 & .282 & 3.944 & .000 \\
EOI & .900 & .137 & .548 & 6.560 & .000 \\
\hline
\end{tabular}

a. Dependent Variable: Relapse

The findings displayed on Table 4 depict significance levels associated with the predictor variables, with hostility having $\beta=-.133(p=0.152>.0 .01)$. The value for criticism was $\beta=.282(p=0.000 \leq .0 .01)$, while the value for EOI was $\beta=.548(\mathrm{p}=0.000 \leq .0 .01)$. Hostility was therefore not significant in predicting for relapse in alcohol dependence, while both criticism and EOI were found to be significant predictors of relapse in alcoholism. Unlike what was hypothesized in the study, the findings demonstrated an inverse relationship between family hostility and relapse in alcoholism. This finding was not expected in the study, given much research in support of the EE-relapse association with hostility as one of the sub-variables of EE. Instead the finding would indicate that the more hostile a family member was to the addicted family member, the lower the chances they were going to relapse. In order to establish the relationship and significance between relapse and hostility, a new regression formula was applied whereby hostility was removed from the model. This would also show the exact 
level of significance of criticism and EOI in relation to relapse in alcohol dependency. Table 5 gives a summary of the findings.

Table 5: Model 2 Summary

\begin{tabular}{|l|c|r|r|r|}
\hline Model & $\mathrm{R}$ & R Square & Adjusted R Square & Std. Error of the Estimate \\
\hline Dimension & $.583^{\mathrm{a}}$ & .340 & .333 & 12.45033 \\
\hline
\end{tabular}

a. Predictors: (Constant), EOI, Criticism

The findings in the revised model 2 on Table 5 showed that the adjusted $\mathrm{R}^{2}$ dropped to 0.340 (from .348 in the earlier model which included hostility), which implied that $34 \%$ of the variations in relapse were adequately explained by family criticism and EOI in this study. This was also an indication that though not significant, hostility had an influence on relapse in alcoholism. The finding demonstrated that in the absence of hostility, EOI and criticism were still strong predictor variables of relapse at 34\%. This meant that though not statistically significant in the regression model, hostility had a role to play in the relapse of an individual recovering from alcohol dependency. The revised model 2 indicated thatcriticism and EOI were strong predictor variables for relapse $(\mathrm{p}=.000 \leq .0 .01)$ in alcoholism. This is summarized on Table 6 .

Table 6: Regression Coefficients Model 2

\begin{tabular}{|c|c|c|c|c|c|c|}
\hline \multirow{2}{*}{\multicolumn{2}{|c|}{ Model }} & \multicolumn{2}{|c|}{ Unstandardized Coefficients } & \multirow{2}{*}{$\begin{array}{c}\begin{array}{c}\text { Standardized } \\
\text { Coefficients }\end{array} \\
\text { Beta }\end{array}$} & \multirow[b]{2}{*}{$\mathrm{T}$} & \multirow[b]{2}{*}{ Sig. } \\
\hline & & $\mathrm{B}$ & Std. Error & & & \\
\hline \multirow[t]{3}{*}{1} & (Constant) & 39.889 & 4.243 & & 9.402 & .000 \\
\hline & Criticism & .794 & .216 & .237 & 3.674 & .000 \\
\hline & EOI & .774 & .106 & .471 & 7.297 & .000 \\
\hline
\end{tabular}

a. Dependent Variable: Relapse

The findings displayed onTable 6 indicate that criticism had a beta coefficient of $\beta=.237(\mathrm{p}=0.000 \leq .0 .01)$, which means that criticism was not only statistically significant but also predicted relapse in alcohol dependence at $23.7 \%$. In other words 1 unit increase in criticism is expected to predict increase in relapse by .237 units. This supports the hypothesis made in the study that family criticism has a positive and strong relationship with relapse of an individual recovering from alcoholism. In the revised model, EOI has a beta coefficient of $\beta=.471(\mathrm{p}=0.000 \leq .0 .01)$, meaning that it was statistically significant and would predict relapse with 1 unit increase in EOI expected to predict increase in relapse by .471 . in this study,EOI had a higher predictive power compared to criticism.

Discussion: The findings of the study show a difference in the prevalence of relapse (39.2\%) of alcoholism as shown in earlier studies in Kenya. For example Deveau, Tengia, Mutua, Njoroge, Dajoh, \& Singer (2010) found an abstinence rate of $42 \%$ with alcohol, cannabis and heroine among outpatient subjects in Kenya.However it is important to note that while this study investigated inpatient individuals with alcoholism who had relapsed and readmitted in treatment centers, Deveau and his colleagues had investigated outpatient subjects.

The findings of this study were consistent with other studiessupporting the EE-relapse association among patients with alcohol dependence (e.g. Pourmand, Kavanagh, \& Vaughan, 2005; Hooley, 2007).Atadokht, Hajloo, Karimi, and Narimani (2014) demonstrated that there was a significant positive relationship $(\mathrm{p}=<0.01)$ between frequency of relapse and family EE among patients who had received treatment for drug abuse. The findings of this study particularly demonstrated that the two components of EE, that is criticism and EOI were strong predictors of relapse in alcoholism.Perceived criticism is interpreted as a threat to being rejected (Hooley $\&$ Teasdale, 1989) and is a powerful predictor of relapse (Hooley \& Gotlib, 2000). Higher levels of perceived criticism have been significantly associated with greater likelihood and a shorter time to relapse (Fals-Stewart, O'Farrell, \& Hooley, 2001). Muskin (1994) had earlier demonstrated that patients with the perception of family criticism were more likely to relapse than those who did not perceive criticism from the family members.

In their diathesis-stress conceptualization of EE, Hooley and Gotlib (2000) claimed that interactions with family members with high EE caused reactions similar to stressful reactions in the sympathetic nervous system, such as high release of cortisol, which might make patients prone to relapse. The argument is that interaction patterns of hostility and criticism (indicating disapproval and dislike)are communicated in an environment depicted by over-caring or self-sacrificing relatives. According to Lopez et al (2009) emotionally over-involved relatives become so overbearing that the patient can no longer live with this kind of stress from pity, and falls back into their illness as a way to cope (Lopez et al, 2009). The emotional reactions eventually wear down the tolerance 
of the addicted individual, which has implications for relapse (Saatcioglu et al., 2006). This results in stressful reactions from for the dependent individual which make them vulnerable to relapse. Systems theorists have debated much on this phenomenon which they refer to as double-bind communication (Visser, 2003) where incongruent messages are given to a patient. Such contradictory messages mean two different things and are likely to confuse the receiver who does not know which of the messages to respond to. In this study, the individual recovering from alcoholism receives too much care but such care is wrapped up within criticism from a close family member. This would mean that the criticism experienced in a high EE family is counterbalanced by emotional over-involvement that may comprise a double-bind for the alcohol-dependent individual (Rotunda and O'Farrell, 1998).

The stress-induced relapse of alcohol use is a well-documented phenomenon (e.g. Brady \& Sonne, 1999; Hooley \& Gotlib, 2000; Janak \& Chaundri, 2010). Exposure to stress is the most powerful and reliable experimental manipulation used on animals to induce return to drinking of alcohol following a period of imposed deprivation (Nesic \& Duka, 2008). Such experiments demonstrated that exposure to stress facilitated both the prompting and reinstatement of reuse of alcohol and other drugs after a period of abstinence (Janak \& Chaundri, 2010). Earlier studies by Brown and his colleagues (1990) indicated that the stress vulnerability is mediated by absence of good social support and was related to relapse after treatment in alcoholism (Brown et al, 1990). One possible explanation for the connection between stress and alcohol use is that stress alters the brain chemistry by modifying the motivational and reinforcing effects of alcohol during neural transmission (Nesic \& Duka, 2008).In addition Nesic and Duka (2008), found out that stress was related to increased negative mood and craving for alcohol due to increase the dopamine activity of brain systems, which are involved with motivation and are likely to relate use of alcohol with rewarding effects.Recovering individuals with alcoholism and other drug addicts may be more susceptible to stress, which can increase their chances of relapses (White \& Jackson, 2005; Fox, Bergquist, Hong \& Sinha, 2007).

Stressful life events and chronic stressors (such as depicted by high EE families) tend to explain the association between stress and relapse. This view is supported by Carlson (2011), who posited that the EE variables of EOI and criticism were so contradicted that they caused confusion which offered a fragile environment that was stressful for the patient, and that could trigger relapse. The self-sacrificing and too caring pattern of behaviour actually becomes destructive (Borovoy, 2005). The overprotective style nurtured dependency and created repressed hostility because it denies individuals autonomy and the much needed opportunities for reality testing (Kumar \& Tiwari, 2008). Families are likely to offer much EOI because they believe that when they get over-involved, they could help win the loyalty of the patient thus he/she may stop the drinking, which instead becomes counterproductive and induces chronic stress. In sum, the main argument made by these studies conclude thatindividuals with alcohol dependency experiencing highly threatening or chronic psychosocial stress (particularly from their families) following treatment were more likely to relapse than abstaining individuals who may not be experiencing such stress. Higley, Crane, Spandoni, Quello, Goodell, \& Mason (2011) have therefore suggested that to improve treatments for alcohol dependence there is need to address high stress levels among the patients. Such high stress may be emanating from the family interactions, due to negative attitudes such as $\mathrm{EE}$, thus determining the direction of alcoholism after treatment.

\section{CONCLUSIONS AND RECOMMENDATIONS:}

This study demonstrated that high expressed emotion (EE), had a significant relationship with relapse in alcoholism. Among the EE variables, EOI had the highest predictive value while hostility had the least significance to relapse in alcoholism. Interventions in alcoholism treatment must realize the seriousness that dysfunctional interactional patterns influence the course of alcoholism particularly in recovery after treatment. Efforts towards educating the family members on healthy communication patterns should be considered throughout the treatment period. Future research would shed more light on the cultural understanding and interpretation of EE variables within different contexts. Other directions to take for future research would be to measure the EE variables with multiple family members to explain if patients gravitate towards particular characteristics of such a family member, for instance the mother-son dyad. One unique quality of this study was the use of data from both the individuals addicted to alcohol and their family member to confirm whether the expressed emotion from a family member was indeed perceived by the receiver. The results of the present study clearly indicate that the family EE as a factor increasing susceptibility to relapse in alcoholism is not unfounded.

\section{REFERENCES}

[1] Marlatt, G. A., Parks, G.A., \& Witkiewitz, K, (2002). Clinical guidelines for implementingrelapse prevention therapy.Alcoholism and Substance Abuse, 12, 1-49.

[2] Witkiewitz, K., \& Marlatt, G. A. (2004). Relapse prevention for alcohol and drugproblems.American Psychologist, 59(4), 224-235. 
[3] Copello, A.G., Velleman, R.D., \& Templeton, L. J. (2005). Family interventions in thetreatment of alcohol and drug problems. Drug Alcohol Review,24(4), 369-385.

[4] Saatcioglu, O., Erim, R., \& Cakmak, D. (2006). Role of Family in alcohol and substance abuse.Review Article, Psychiatry and Neurosciences, 60(2), 125-132.

[5] Beattie, M. C. (2001). Meta-analysis of social relationships and post treatment drinkingoutcomes: Comparison of relationship structure, function and quality. Journal of Studies in Alcohol, 62(4), 518527.

[6] Minuchin, S. (1974). Families and Family Therapy. Massachusetts: Harvard University Press,Cambridge.

[7] L'Abate, L. (Ed.). (1998). Family psychopathology: The relational roots of dysfunctional behaviour. New York: Guilford Press.

[8] West, R. (2006). Theory of addiction. Massachusetts: Blackwell.

[9] Nichols, M. P., \& Schwartz, R. C. (2006). Family therapy: Concepts and methods. New York:Pearson.

[10] Goldenberg, I., \& Goldenberg, H. (2000). Family therapy: An overview (5 ${ }^{\text {th }}$ ed.). Belmont, CA:Waldsworth/Thomson Learning.

[11] Pierce, R., Frone, M., Russell, M., Cooper, M., \& Mudar P. (2000). A longitudinal model ofsocial contact, social support, depression, and alcohol use. Health Psychology, 91(1), 28-38.

[12] Antoine, P., Christophe, V., \& Nandrino, J. (2009). Crossed evaluations of temptation to drink, strain and adjustment in couples with alcohol problems. Journal of Health Psychology, 14(8), 1156-1162.

[13] Orford, J., Velleman, R., Copello, A., Templeton, L., \& Ibanga, A. (2010). The experiences of affected family members: A summary of two decades ofqualitative research. Drugs, Education, Prevention and Policy, 17(1), 44-62.

[14] Raitasalo, K., \& Holmila, M. (2005). The role of the spouse in regulating one's drinking. Addiction Research and Theory, 13(2), 137- 144.

[15] Fals-Stewart, W., O’Farrell, T. J., Birchler, G. R., Cordova, J., \& Kelley, M. L.(2005).Behavioural couples therapy for alcoholism and drug abuse: Where we have been, where we are, and where we are going. Journal of Cognitive Psychotherapy, 19(3), 229-246.

[16] Hunter-Reel, D., McCrady, B., \& Hildebrandt, T. (2009).Emphasizinginterpersonal factors: Anextension of the Witkiewitz and Marlatt relapse model. Addiction, 104(8), 1281-1290.

[17] Collins, R.L. (1990). Family treatment of alcohol abuse: Behavioural systems perspective. In R.L. Collins, K.E. Leonard, \& J. S. Searles (Eds.).Alcohol and the family: Research and clinical perspectives (pp. 338-355). New York: Guilford.

[18] Rotunda, R.J., \& O'Farrell, T.J. (1998). Understanding and managing expressed emotion in the couples' treatment of alcoholism. Psychotherapy in Practice, 4(3), 55-71.

[19] Hooley, J. M. (2007). Expressed emotion and relapse of psychopathology. Annual Review of Clinical Psychology, 3, 329-352.

[20] Simmons, R. A., Chambless, D. L., \& Gordon, P. C. (2008). How do hostile and emotionallyoverinvolved relatives view relationships? What relatives'pronoun use tell us. FamilyProcess, 47(3), 405-419.

[21] Hooley, J.M., \& Gotlib, I. H. (2000). ADiathesis-stress conceptualization of clinical outcome. Applied and PreventivePsychology, 9(3), 135-151.

[22] Brewin, C. R., MacCarthy, B., Duda, K., \& Vaughn, C. E. (1991). Attribution of expressed emotion in the relatives of patients with schizophrenia. Journal of Abnormal psychology, 100, 546-554.

[23] Carlson, R. G. (2011). Communication deviance, expressed emotion, and family cohesion in schizophrenia. Open Access Dissertations, $\quad$ Paper 615.

[24] Ikram, A., Suhail, K., Jeffery, S. Z., \& Singh, S. (2011). Rates of expressed emotion in Pakistan relatives of patients with schizophrenia. Israel Journal of Psychiatry and Related Sciences, 48(2), 74-81.

[25] Ng, R. M. K., Mui, J., Cheung, H. K., \& Leung, S. P. (2001). Expressed emotion andrelapse of schizophrenia in Hong Kong. Hong Kong Journal of Psychiatry, 11(1), 4-11.

[26] Klaus, N., \& Fristad, M. A. (2005). Family Psycho-education: An adjunctive intervention forchildren with bipolar disorder. Directions in Psychiatry, 25(3), 217-229.

[27] Kwon, J., Lee, Y., Lee M. \& Bifulco, A. (2006). Perceived criticism, marital interaction and relapse in unipolar depression- findings from a Korean sample. Clinical Psychology and Psychotherapy, 13, 306-312.

[28] Chambless, D.L., \& Steketee, G. (1999). Expressed emotion and behaviour therapy outcome. A prospective study with obsessive- compulsive andagoraphobic outpatients. Journal ofConsulting and Clinical Psychology, 67(5), 658-665.

[29] Santos, J. C., Saraiva, C. B., \& De Sousa, L. (2009). The role of expressed emotion, self- concept, Coping, and depression in parasuicidal behavior: A follow-up study. Archives of $\quad$ Suicide Research, 13, 358-367. 
[30] Azhar, M. Z., \& Varma, S. L. (1996). Relationship of expressed emotion with relapse of schizophrenia patients in Kelantan. Singapore Medical Journal, 37(1), 82-85.

[31] Lopez, S. R., Ramirez, G. J., Ullman, J. B., Kopelowicz, A., Jenkins, J., Breitborde, N. J., \&Placenia, P. (2009). Cultural variability in the manifestation of expressed emotion.Family Process, 48(2), 179-194.

[32] O'Farrell, T. J., Hooley, J., Fals-Stewart, W., \& Cutter, H. (1998). Expressed emotion andrelapse in alcoholic patients. Journal of Consulting and Clinical Psychology, 66(5), 744-754.

[33] Fichter, M. M., Glynn, S. M., Weyerer, S., Lieberman, R. P. \& Frick, U. (1997). Family climateand expressed emotion in the course of alcoholism. Family Process, 36(2), 203-221.

[34] Pugovkina, O.D., \& Popinako, A. V. (2014). Psychological factors of propensityforalcoholism (social anxiety, hostility, Machiavellianism) in depressive patients. Psychology in Russia: State of the Art, 7(2), 73-83.

[35] Pourmand, D., Kavanagh, D. J. and Vaughan, K. (2005), Expressed emotion as predictor ofrelapse in patients with comorbid psychoses and substance use disorder. Australian and New Zealand Journal of Psychiatry, 39(6), 473-478.

[36] Renshaw, K. D., Blais, R. K., \& Caska, C. M. (2010). Distinctions between hostile and non-hostile forms of perceived criticism from others. Behaviour Therapy, 41(3), 364-374.

[37] Deveau, C. S., Tengia, L., Mutua, C., Njoroge, S., Dajoh, L., \& Singer, B. (2010).Utilization of community-based outpatient addiction treatment programmes in Kenya. African Journal of Drug and Alcohol Studies, 9(2), 62-70.

[38] Atadokht, A, Hajloo, N., Karimi, M., \& Narimani, M. (2014). The role of family expressed emotion and perceived social support in predicting addiction relapse. International Journal of High Risk

Behaviours and Addiction. 4 (1) 1-5.

[39] Hooley, J. M.,\& Teasdale, J. D. (1989). Predictors of relapse in unipolar depressives: Expressed emotion, marital distress, and perceived criticism. Journal of Abnormal Psychology, 98, 229-235.

[40] Fals-Stewart, W., O'Farrell, T.J., \& Hooley, J. M. (2001). Relapse among married or cohabiting substance-abusing patients: The role of perceived criticism. Behaviour Therapy, 32, 787-801.

[41] Muskin, P. R. (1994). Expressed emotion, perceived criticism, and relapse in depression: A replication in an Egyptian community. The American Journal of Psychiatry. 151(7) 1001-1005.

[42] Visser, M. (2003). Gregory Bateson on deuteron-learning and double-bind: A brief conceptual history. Journal of History of the Behavioural Sciences, 39(3), 269-278).

[43] Brady, K.T., Sonne, S. C. (1999). The role of stress in alcohol use, alcoholism treatment, and relapse. Alcohol Research and Health, 23(4), 263-271.

[44] Janak, P. H., \& Chaunhri, N. (2010). The potent effect of environmental context on relapse to alcohol seeking after extinction. The Open Addiction Journal, 3, 76-87.

[45] Nesic, J., \& Duka, T. (2008). Effects of stress on emotional reactivity in hostile heavy social drinkers following dietary tryptophan enhancement. Alcohol \&Alcoholism, 40(2), 151-162.

[46] Brown S.A., Vik, P. W., McQuaid, J. R., Patterson, T. L., Irwin, \& Grant, I. (1990). Severity of psychosocial stress and outcome of alcohol treatment. Journal of Abnormal Psychology,99, 344-348.

[47] White , H. R., \& Jackson, K. (2005). Social and Psychological influences on emergingadultdrinking behavior. Alcohol research and health 28(4), 182-190.

[48] Fox, H. C., Bergquist, K. L., Hong, K., \& Sinha, R. (2007). Stress-Induced and Alcohol CueInduced Craving in Recently Abstinent Alcohol-Dependent Individuals. Alcoholism: Clinical and Experimental Research, 31(3), 395-403.

[49] Borovoy, A. (2005). The Too-Good Wife: Alcohol, Codependency, and the Politics of Nurturance in Postwar Japan. Berkeley: University of California Press.

[50] Kumar P. \& Tiwari, S. C. (2008). Family and psychopathology: An overview Series-1: Children and adults. Delhi Psychiatry Journal, 11 (2), 140-149.

[51] Higley, A. E., Crane, N.A., Spandoni, A.D., Quello, S. B., Goodell, V., \& Mason, B. J. (2011). Craving in response to stress induction in a human laboratory paradigm predicts treatment outcome in alcohol dependent individuals. Psychophamacology, 218(1), 121-129. 